\title{
openheart Health utility indexes in patients with acute coronary syndromes
}

\author{
Baris Gencer, ${ }^{1}$ Nicolas Rodondi, ${ }^{2}$ Reto Auer, ${ }^{3}$ David Nanchen, ${ }^{3}$ Lorenz Räber, ${ }^{4}$ \\ Roland Klingenberg, ${ }^{5}$ Mark Pletscher, ${ }^{6}$ Peter Jüni, ${ }^{7,8}$ Stephan Windecker, ${ }^{4}$ \\ Christian M Matter, ${ }^{5}$ Thomas F Lüscher, ${ }^{5}$ François Mach, ${ }^{1}$ Thomas V Perneger, ${ }^{9}$ \\ François R Girardin ${ }^{10,11}$
}

To cite: Gencer B, Rodondi N, Auer R, et al. Health utility indexes in patients with acute coronary syndromes. Open Heart 2016:3:e000419. doi:10.1136/openhrt-2016000419

Received 4 February 2016 Revised 15 March 2016 Accepted 25 April 2016
CrossMark

For numbered affiliations see end of article.

Correspondence to

Dr Baris Gencer;

Baris.Gencer@hcuge.ch

\section{ABSTRACT}

Background: Acute coronary syndromes (ACS) have been associated with lower health utilities (HUs) compared with the general population. Given the prognostic improvements after ACS with the implementation of coronary angiography (eg, percutaneous coronary intervention (PCI)), contemporary $\mathrm{HU}$ values derived from patient-reported outcomes are needed.

Methods: We analysed data of 1882 patients with ACS 1 year after coronary angiography in a Swiss prospective cohort. We used the EuroQol fivedimensional questionnaire (EQ-5D) and visual analogue scale (VAS) to derive $\mathrm{HU}$ indexes. We estimated the effects of clinical factors on HU using a linear regression model and compared the observed $\mathrm{HU}$ with the average values of individuals of the same sex and age in the general population.

Results: Mean EQ-5D HU 1-year after coronary angiography for ACS was $0.82( \pm 0.16)$ and mean VAS was 0.77 ( \pm 0.18 ); $40.9 \%$ of participants exhibited the highest utility values. Compared with population controls, the mean EQ-5D HU was similar (expected mean $0.82, p=0.58$ ) in patients with ACS, but the mean VAS was slightly lower (expected mean $0.79, p<0.001$ ). Patients with ACS who are younger than 60 years had lower HU than the general population $(<0.001)$. In patients with ACS, significant differences were found according to the gender, education and employment status, diabetes, obesity, heart failure, recurrent ischaemic or incident bleeding event and participation in cardiac rehabilitation $(p<0.01)$.

Conclusions: At 1 year, patients with ACS with coronary angiography had $\mathrm{HU}$ indexes similar to a control population. Subgroup analyses based on patients' characteristics and further disease-specific instruments could provide better sensitivity for detecting smaller variations in health-related quality of life.

\section{INTRODUCTION}

Acute coronary syndromes (ACS) remain one of the leading causes of mortality and morbidity in European countries. ${ }^{1}$ The implementation of recommended therapies, such as percutaneous coronary intervention

\section{KEY QUESTIONS}

What is already known about this subject?

- Acute coronary syndromes (ACS) remain one of the leading causes of mortality and morbidity in European countries. The implementation of recommended therapies, such as percutaneous coronary intervention, effective pharmacological agents and cardiac rehabilitation programs have considerably reduced the incidence of major adverse cardiac and cerebrovascular event. However, patients with ACS may suffer from limitations in physical and functional activities impacting on health utility.

What does this study add?

- The main results in the present study were that health utility values measured with the EuroQol questionnaire five dimensions (EQ-5D) in ACS patients referred for coronary angiography were similar to the general population, while self-rated health status measured by visual analog scale was significantly lower. Impact of ACS on health utility and self-reported health status was especially pronounced in patients with premature ACS. Significant differences of health utility were found according to gender, education, employment status, and presence of diabetes, obesity, heart failure, recurrent ischemic or incident bleeding events and attendance to cardiac rehabilitation. These findings could potentially strengthen utility estimates (i.e. model input parameters) and update further cost-effectiveness analyses on coronary procedures, particularly if health utility estimates are required for specific subgroups of ACS patients.

How might this impact on clinical practice?

- Our results suggest that $E Q-5 D$ health utility values are not lower in ACS patients referred for coronary angiography compared to the general population, except for patients with premature ACS. This study shows the favorable impacts of contemporary ACS management, including percutaneous coronary intervention or cardiac rehabilitation, but also the dramatic impact of premature ACS. During the follow-up, patients who presented adverse events after ACS (recurrence of ischemic or bleeding events) have significantly lower health utility, as well as those with lower educational status. 
(PCI), effective pharmacological agents and cardiac rehabilitation (CR) programmes have considerably reduced the incidence of major adverse cardiac and cerebrovascular events (MACCE). ${ }^{2}$ Patients with ACS may suffer from limitations in physical and functional activities impacting on their health utility (HU). ${ }^{3} 4$

$\mathrm{HU}$ is a driving parameter in health economic studies guiding clinical and policy decision-making. ${ }^{5}$ Indeed, integrating $\mathrm{HU}$ into medical decisions or treatment outcome is recommended by the European guidelines for ACS management. ${ }^{6}$ The EuroQol five-dimensional questionnaire (EQ-5D) is a common framework used to translate different dimensions of health-related quality of life into a single $\mathrm{HU}$ value. Previous studies using EQ-5D HU have shown lower HU in patients with coronary artery disease (CAD), especially in socioeconomically vulnerable patients. ${ }^{3}{ }^{78}$ Information about the average HU values and their determinants in patients with ACS are often used in economic evaluation studies on ACS. However, a review of cost-effectiveness analyses found that $77 \%$ of studies did not incorporate communitybased preferences and 33\% used arbitrary expert elicitation. ${ }^{7}$ Recent cost-effectiveness studies in coronary patients were based on $\mathrm{HU}$ values (eg, quality-adjusted life-years) from the 1990s when the PCI was less frequently used than today. ${ }^{9}{ }^{10}$ In this study, we aimed to assess contemporary $\mathrm{HU}$ in a prospective cohort of patients with ACS and compare the values with those of the general population localised in the same region. ${ }^{11}$

\section{METHODS}

\section{Study population with ACS}

The Multi-dimensional Prevention Programme after Acute Coronary Syndrome (ELIPS, study identifier NCT01075867) is a prospective cohort of patients enrolled with a main diagnosis of ACS in four Swiss University Hospitals (Bern, Geneva, Lausanne and Zürich). ${ }^{12} 13$ The cohort includes patients referred for coronary angiography between September 2009 and December 2012. ${ }^{14}$ Exclusion criteria comprised index revascularisation with coronary artery bypass graft (CABG), inability to give informed consent and life expectancy $<1$ year (for non-cardiac reasons). The study protocol was approved by the local ethics committees, and all participants provided written informed consent.

\section{Data collection}

Participants were contacted by a trained study nurse for a clinical visit 1 year after the ACS at the enrollment site. If patients were unable to attend the consultation personally, the data collection was performed in the following order: (1) over the phone, (2) by mail or email, (3) through family members and finally (4) through the primary care physician. We collected baseline data on sociodemographic characteristics, cardiovascular history, cardiovascular risk factors, cardiovascular medication and participation in cardiac rehabilitation (CR). During the follow-up visit, we assessed the incidence of MACCE, such as the overall mortality, recurrence of myocardial infraction (MI), stroke, hospitalisation for unstable angina and peripheral artery disease. We also collected data on bleeding events using the standardised definition. ${ }^{15}$ All events were adjudicated by a panel of certified cardiologists, based on the medical records.

\section{Measurement of HU}

HU in the ELIPS cohort was measured using the validated EQ-5D questionnaire during the 1-year follow-up visit. In addition, the instrument includes a VAS, represented by a vertical scale. The EQ-5D questionnaire consists of five questions, each representing one dimension. These five dimensions are mobility, self-care, usual activities, pain, discomfort, anxiety and depression. For each dimension, participants were asked to report their status on a three-level ordinal scale: no problems, some problems or severe problems. Health states among the 243 possible combinations from the EQ-5D questionnaire index were translated to $\mathrm{HU}$ index for each respondent using a standard pan-European value set. ${ }^{16} \mathrm{HU}$ is measured on a scale between 0 and 1,1 representing perfect health and 0 representing death. To compare the estimates of HU in our cohort with those obtained in the general population, we used the previously published reference values from among the 1952 randomly selected adults in the French-speaking part of Switzerland. ${ }^{11}$

\section{Statistical analysis}

The primary end point was the EQ-5D-derived HU index and self-rated health status using VAS results 1 year after hospitalisation for ACS. We presented the frequency distributions of the EQ-5D items and the mean values and SDs of HU and VAS results. The average $\mathrm{HU}$ and VAS results were presented for different clinically relevant subgroups. ${ }^{6}$ We used $\chi^{2}$ tests for dichotomous outcomes and t-tests for continuous outcomes. A multiple linear regression model was estimated to study the association between HU and VAS values and patient characteristics (age, sex, education and working status), clinical parameters (body mass index (BMI), diabetes, hypertension, signs of heart failure (HF), heart rate, type of ACS), CR and the occurrence of adverse events defined by the combination of MACCE or bleeding events. The selection of variables was defined prior to the statistical analysis and was based on clinical judgment and previous publication. ${ }^{17}$ Age was categorised into the following groups: $<50,50-59,60-69,70-79$ and $\geq 80$ years old as performed in a previous publication on the general population; ${ }^{11}$ BMI into three categories of normal weight $\left(<25 \mathrm{~kg} / \mathrm{m}^{2}\right)$, overweight $(25-29.9 \mathrm{~kg} /$ $\mathrm{m}^{2}$ ) and obesity $\left(\geq 30.0 \mathrm{~kg} / \mathrm{m}^{2}\right)$; heart rate estimated were presented for an increase of each $10 \mathrm{bpm}$. The individual outcomes of $\mathrm{HU}$ and VAS in the surveyed patients with ACS 1 year after coronary angiography were compared with the predicted values of these 
patients if they were average members of the general population. The predicted values of identical individuals in the general population were calculated using a published prediction equation estimated for Switzerland. ${ }^{11}$ The prediction equations included age, age squared and sex: HU $=0.84822-0.00208 \times($ age -50$)-0.00002 \times(\text { age }-50)^{2}$ -0.02090 if female for EQ-5D utilities and VAS=83.183 $-0.199 \times($ age -50$)-0.006 \times(\text { age }-50)^{2}+0.401$ if female for VAS self-assessed utilities. These equations allow the computation of individual expected values without the problems posed by small samples within strata and by discrete jumps between strata. We reported the differences of the observed minus predicted outcomes of the mean EQ-5D HU and VAS and then used a parametric one-sample t-test.

\section{RESULTS}

\section{Baseline characteristics}

Of the 2352 patients enrolled at baseline for angiography during the index ACS event from September 2009 to December 2012, 50 (2.2\%) died; $49(2.1 \%)$ refused the follow-up; 41 were lost to follow-up (1.7\%); 84 (3.6\%) had a follow-up beyond 450 days and 245 (11.2\%) had missing data for fully completed EQ-5D items, yielding to a final sample of 1882 participants for primary analysis. Mean age was 62.0 (11.8); $79.8 \%$ were men; $16.6 \%$ had diabetes; $53.6 \%$ had hypertension; $20.8 \%$ were obese and $1308(70.6 \%)$ attended a CR programme after hospital discharge (table 1).

\section{Description of HU}

In the overall ACS study population, the mean EQ-5D was $0.82(0.16)$ for HU and VAS was 0.77 (0.17) (table 2).

It has been estimated that $40.9 \%$ of all patients with ACS reported the highest utility values in all five EQ-5D dimensions; $16.3 \%$ of patients with ACS had problems with mobility, $3.5 \%$ with self-care, $15.9 \%$ with daily activities, $45.8 \%$ had pain or discomfort and $33.0 \%$ suffered from anxiety or depression (table 2). The highest bound of VAS was lower among patients who reported the highest utilities in all five EQ-5D dimensions compared with $\mathrm{HU}$ (0.86 vs $0.98, \mathrm{p}<0.001)$.

\section{Clinical characteristics of patients with ACS and HU at 1 year}

In subgroup analyses, we found that $\mathrm{HU}$ (0.83 vs 0.77 , $\mathrm{p}<0.001)$ and VAS $(0.77$ vs $0.73, \mathrm{p}<0.001)$ at 1 year were significantly lower in women (table 2). Patients who attended a CR programme after hospital discharge reported significantly higher $\mathrm{HU}$ ( 0.83 vs $0.79, \mathrm{p}<0.001$ ) and VAS $(0.74$ vs $0.78, \mathrm{p}<0.001) 1$ year after ACS, while patients who presented the occurrence of MACCE or a bleeding event after the index ACS reported lower HU ( 0.78 vs $0.82, \mathrm{p}<0.001)$ and VAS (0.71 vs $0.77, \mathrm{p}<0.001)$ at 1 year. The multivariate linear regression model suggested that women, low educational status, unemployment or retired status, patients with obesity, diabetes,

\begin{tabular}{|c|c|}
\hline \multicolumn{2}{|l|}{ Demographics } \\
\hline Age, mean $( \pm S D)$ & $62.0(11.8)$ \\
\hline Male & 1501 (79.8) \\
\hline University education, & $284(15.5)$ \\
\hline Married or partnership & $1274(67.8)$ \\
\hline No employment or retired & $899(48.1)$ \\
\hline Living with someone & 1445 (76.9) \\
\hline \multicolumn{2}{|l|}{ CVRF or medical history } \\
\hline \multicolumn{2}{|l|}{ BMI $\left(\mathrm{kg} / \mathrm{m}^{2}\right)$ categories, $\mathrm{n}(\%)$} \\
\hline$<25 \mathrm{~kg} / \mathrm{m}^{2}$ & $600(32.3)$ \\
\hline $25.0-29.9 \mathrm{~kg} / \mathrm{m}^{2}$ & 865 (78.9) \\
\hline$\geq 30.0 \mathrm{~kg} / \mathrm{m}^{2}$ & $392(21.1)$ \\
\hline Current smoking & 748 (39.7) \\
\hline Diabetes & $313(16.6)$ \\
\hline Hypercholesterolaemia & $1146(61.0)$ \\
\hline Hypertension & 1009 (53.6) \\
\hline Previous MI & 269 (14.3) \\
\hline \multicolumn{2}{|l|}{ Hospitalisation data } \\
\hline \multicolumn{2}{|l|}{ ACS diagnosis } \\
\hline Unstable angina, n (\%) & $84(4.5)$ \\
\hline NSTEMI, $\mathrm{n}(\%)$ & 746 (39.6) \\
\hline STEMI, n (\%) & 1052 (55.9) \\
\hline \multicolumn{2}{|l|}{ Index revascularisation } \\
\hline $\mathrm{PCl}$ with stent & $1642(87.3)$ \\
\hline $\mathrm{PCl}$ with balloon & $100(5.3)$ \\
\hline Conservative & $140(7.4)$ \\
\hline \multicolumn{2}{|l|}{ Killip classification } \\
\hline Killip 1 & 1675 (89.9) \\
\hline Killip 2 & $131(7.0)$ \\
\hline Killip 3 & 25 (1.3) \\
\hline Killip 4 & $32(1.7)$ \\
\hline \multicolumn{2}{|l|}{ Discharge data } \\
\hline Attendance to CR, n (\%) & $1308(70.6)$ \\
\hline Documentation of aspirin, n (\%) & $1881(100)$ \\
\hline $\begin{array}{l}\text { Documentation of } \mathrm{P} 2 \mathrm{Y} 12 \text { inhibitors } \\
\text { if } \mathrm{PCl}, \mathrm{n}(\%)\end{array}$ & $1684(99.5)$ \\
\hline Documentation of statin, $\mathrm{n}(\%)$ & 1861 (98.9) \\
\hline Documentation of $\beta$-blocker, $n(\%)$ & $1764(93.7)$ \\
\hline Documentation of ACEI/ARB, $n(\%)$ & 1875 (99.6) \\
\hline \multicolumn{2}{|c|}{$\begin{array}{l}\text { ACS, acute coronary syndromes; ACEI, ACE inhibitors; ARB, } \\
\text { angiotensin receptor blocker; BMM, body mass index; CABG, } \\
\text { coronary artery bypass grafting; CR, cardiac rehabilitation; CVRF, } \\
\text { cardiovascular risk factor; EQ-5D, EuroQol five-dimensional } \\
\text { questionnaire; Killip, MI, myocardial infarction; NSTEMI, } \\
\text { Non-ST-elevation myocardial infarction; PCI, percutaneous } \\
\text { coronary intervention; STEMI, ST-elevation myocardial infarction; } \\
\text { UA, unstable angina. }\end{array}$} \\
\hline
\end{tabular}

hypertension, heart failure symptoms and persisting elevated heart rate are significant predictors of low HU and VAS self-rated health status 1 year after ACS (table 3). In addition, patients who presented MACCE or bleeding events during the year (from baseline to the 1-year follow-up) experienced an additional decrement in their $\mathrm{HU}$ at 1 year. On the contrary, attendance to a CR programme after hospital discharge was associated with significantly higher $\mathrm{HU}$. The coefficients of the multivariable model were similar both for EQ-5D HU and VAS outcomes. 
Table 2 Subgroup comparisons of the EQ-5D questionnaires in 1882 patients 1 year after coronary angiography for ACS

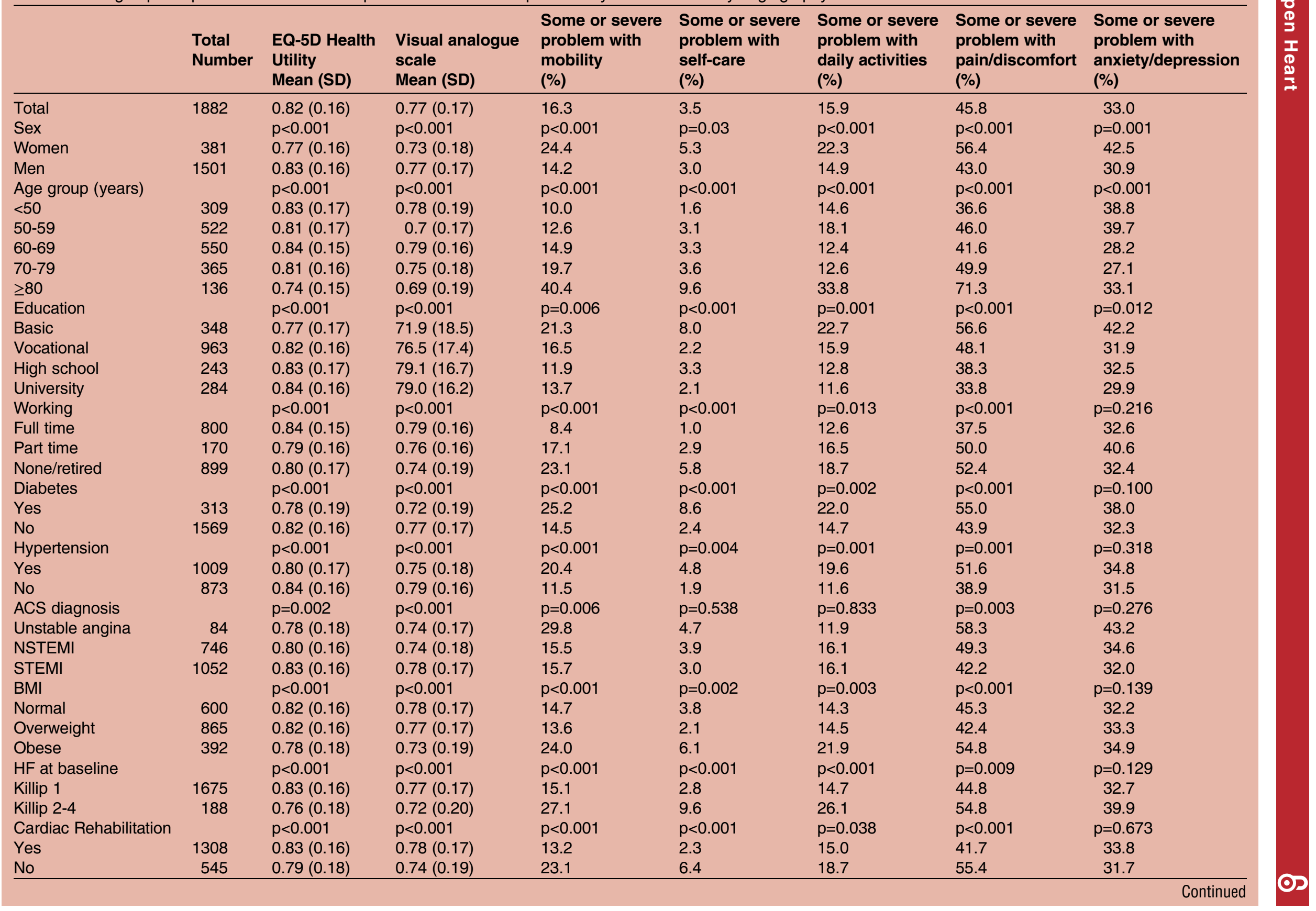




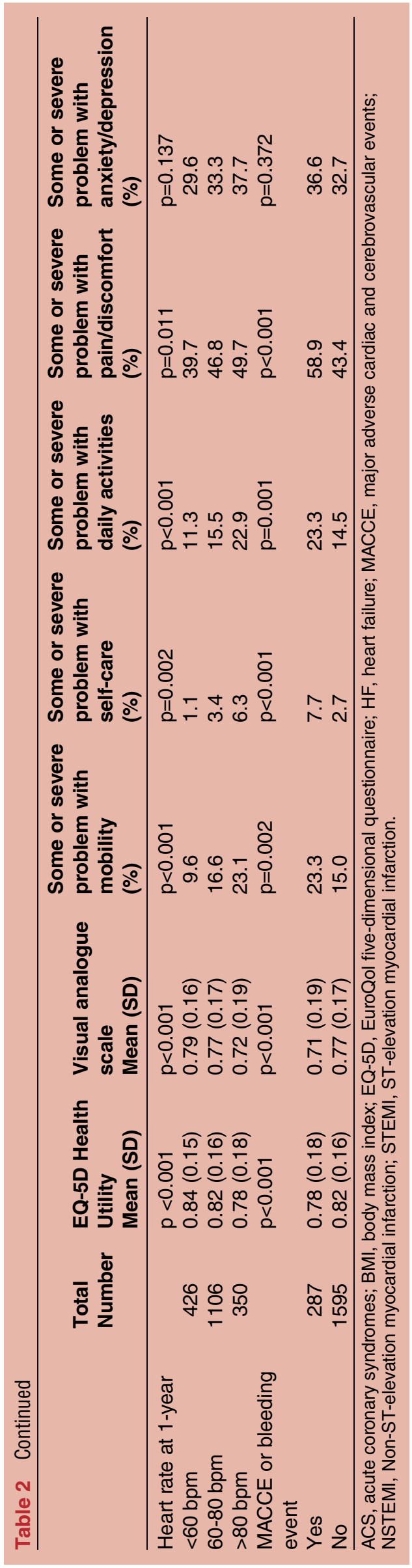

\section{Comparison of $\mathrm{HU}$ with the general population}

We did not find significant differences between the average $\mathrm{HU}$ in the patient with ACS cohort and the average predicted values from the equation of the general population ( 0.82 vs $0.82, p=0.577)$ (table 4$)$. No differences were found according to sex, but HU was significantly lower in patients with ACS younger than 60 years $(-0.03, \mathrm{p}<0.001)$ compared with the control groups. Regarding self-rated health status, we found significant differences between the observed and predicted values of VAS $(0.76$ vs $0.79, \mathrm{p}<0.001)$, especially in patients younger than 60 years old $(-0.06, \mathrm{p}<0.001)$.

\section{DISCUSSION}

The main results in this study were that HU values in patients with ACS referred for coronary angiography were similar to the general population, while self-rated health status measured by VAS was significantly lower. The impact of ACS on HU and self-reported health status was especially pronounced in patients younger than 60 years old. Significant differences of $\mathrm{HU}$ were found according to gender, education, employment status, presence of diabetes, obesity, heart failure, recurrent ischaemic or incident bleeding events and attendance to cardiac rehabilitation. These findings could potentially strengthen utility estimates (ie, model input parameters) and update further cost-effectiveness analyses on coronary procedures, particularly if $\mathrm{HU}$ and quality-of-life estimates are required for specific subgroups of patients with ACS.

A wide range of $\mathrm{HU}$ instruments yield various score amplitudes and discriminate more precisely the treatment differences. In the 1 -year results of the third Randomised Intervention Trial of unstable Angina (RITA-3), VAS scores were better for interventional strategy than for conservative at 4 months (treatment difference of 3.0, p<0.001) and 1 year $(2.3, \mathrm{p}<0.01)$ and the EQ-5D utility scores were less statistically significant at 4 months (treatment difference: 0.036, $\mathrm{p}<0.01$ ) and not significant at 1 year $(0.016, \mathrm{p}=0.20) .{ }^{18}$ Although the ease of VAS use also provides information on patients' global state of well-being and allows comparability of relative health state across various illnesses, other disease-specific instruments would provide greater sensitivity for detecting the tiny variations in quality-of-life estimates and information on the influence of various factors on HU. ${ }^{19} 20$

Further patient-reported outcome studies could confirm the important issue of whether or not the disutility due to ACS differs significantly across subgroups. These specificities are scantly reported in costeffectiveness analyses and clinical trials, although differences of health status were observed according to vulnerability in patients with $\mathrm{CAD} .^{3}$

In the multivariate analysis, attendance to cardiac rehabilitation was significantly associated with higher estimates of HU. This result is in line with findings from 
Table 3 Multivariate model of associated factors with health utility and self-rated health status in 1882 patients 1 year after coronary angiography for ACS

\begin{tabular}{|c|c|c|c|c|}
\hline \multirow[b]{2}{*}{ Variables } & \multicolumn{2}{|c|}{ EQ-5D health utility } & \multicolumn{2}{|l|}{ VAS } \\
\hline & Coefficient & p Value & Coefficient & p Value \\
\hline \multicolumn{5}{|l|}{ Sociodemographics } \\
\hline \multicolumn{5}{|l|}{ Age categories (years old) } \\
\hline$<50$ & Ref & & & \\
\hline $50-59$ & -0.007 & 0.566 & -0.007 & 0.5622 \\
\hline $60-69$ & 0.050 & $<0.001$ & 0.063 & $<0.001$ \\
\hline $70-79$ & 0.050 & 0.002 & 0.058 & 0.001 \\
\hline$>80$ & 0.003 & 0.878 & 0.12 & 0.576 \\
\hline Women & -0.026 & 0.016 & -0.014 & 0.205 \\
\hline \multicolumn{5}{|l|}{ BMI categories } \\
\hline Normal $\left(<25.0 \mathrm{~kg} / \mathrm{m}^{2}\right)$ & Ref & & Ref & \\
\hline Overweight $\left(25.0-29.9 \mathrm{~kg} / \mathrm{m}^{2}\right)$ & 0.002 & 0.866 & -0.006 & 0.533 \\
\hline Obese $\left(\geq 30.0 \mathrm{~kg} / \mathrm{m}^{2}\right)$ & -0.034 & 0.002 & -0.038 & 0.001 \\
\hline \multicolumn{5}{|l|}{ Education level } \\
\hline Lower than vocational & Ref & & Ref & \\
\hline Vocational & 0.031 & 0.004 & 0.033 & 0.003 \\
\hline High school & 0.037 & 0.008 & 0.050 & 0.001 \\
\hline University & 0.043 & 0.002 & 0.042 & 0.004 \\
\hline \multicolumn{5}{|l|}{ Working status } \\
\hline Full time & Ref & & & \\
\hline Part time & -0.039 & 0.007 & -0.022 & 0.156 \\
\hline No employment/retired & -0.045 & $<0.001$ & -0.050 & $<0.001$ \\
\hline \multicolumn{5}{|l|}{ Medical conditions at baseline } \\
\hline History of diabetes & -0.029 & 0.007 & -0.035 & 0.005 \\
\hline History of hypertension & -0.021 & 0.012 & -0.171 & 0.058 \\
\hline \multicolumn{5}{|l|}{ ACS diagnosis } \\
\hline Unstable angina & Ref & & Ref & \\
\hline NSTEMI & 0.023 & 0.237 & -0.010 & 0.645 \\
\hline STEMI & 0.029 & 0.148 & 0.005 & 0.808 \\
\hline \multicolumn{5}{|l|}{ Baseline heart failure } \\
\hline Killip 1 & Ref & & Ref & \\
\hline Killip 2-4 & 0.043 & 0.001 & 0.042 & 0.002 \\
\hline \multicolumn{5}{|l|}{ Preventive intervention } \\
\hline Cardiac rehabilitation & 0.022 & 0.018 & 0.023 & 0.020 \\
\hline \multicolumn{5}{|l|}{ One-year outcomes } \\
\hline MACCE or bleeding events & -0.031 & 0.005 & -0.048 & $<0.001$ \\
\hline Heart rate at 1 year (per $10 \mathrm{bpm}$ at rest) & -0.009 & 0.017 & -0.012 & 0.002 \\
\hline
\end{tabular}

previous studies showing that good medication compliance, regular physical activity, risk factor modification and patient-centered care are associated with higher HU. ${ }^{17}$ Indeed, randomised controlled trials in patients with ACS do generally not report the rates of CR attendance. We also observed that obesity, diabetes and factors of poor adherence to a healthy lifestyle were associated with lower HU. At the time of inclusion, about $10 \%$ of participants had signs of HF. In the multivariate model, HF signs and persisting elevated heart rate were significantly associated with poorer $\mathrm{HU}$ and self-reported health status. Since it is likely that patients with decompensate $\mathrm{HF}$ are under-represented in clinical trials (eg, in PLATO trial, $1 \%$ of patients had Killip $>2$ at the inclusion), these patient-reported outcome added valuable information on real-life representation after ACS. $^{21}$ Regarding gender issue, in a recent cohort of patients with premature ACS, women reported worse HU than men in the domain of physical and mental functioning, suggesting that cultural and social role of women could have a negative impact on $\mathrm{HU}^{22}$ In our study, the lower $\mathrm{HU}$ in women remained present and statistically significant even after adjustment for clinical variables. Regarding socioeconomic factors, we found that patients with lower education and employment had worse EQ-5D HU.

Recent cost-effectiveness studies assessing the revascularisation strategies in patients with $\mathrm{CAD}$ derived estimates from data published in the 1990s. ${ }^{9}{ }^{23}$ In the USA, reference values for patients with CAD were defined as a 
Table 4 Differences between observed and predicted mean values of health utility and self-reported health status. In 1882 patient 1 year after coronary angiography for ACS

\begin{tabular}{|c|c|c|c|c|}
\hline & \multicolumn{2}{|l|}{ EQ-5D health utility } & \multicolumn{2}{|l|}{ Visual analogue scale } \\
\hline & $\begin{array}{l}\text { Differences } \\
\text { observed-predicted* } \\
\text { Mean (SD) }\end{array}$ & p Valuet & $\begin{array}{l}\text { Differences } \\
\text { observed-predicted¥ } \\
\text { Mean (SD) }\end{array}$ & p Value \\
\hline Total & $0.00(0.16)$ & 0.577 & $-0.03(0.18)$ & $<0.001$ \\
\hline \multicolumn{5}{|l|}{ Sex } \\
\hline Women & $-0.01(0.17)$ & 0.281 & $-0.05(0.18)$ & $<0.001$ \\
\hline Men & $0.00(0.16)$ & 0.235 & $-0.02(0.18)$ & $<0.001$ \\
\hline \multicolumn{5}{|c|}{ Age group (years) } \\
\hline$<50$ & $-0.03(0.17)$ & 0.004 & $-0.06(0.19)$ & $<0.001$ \\
\hline $50-59$ & $-0.03(0.17)$ & $<0.001$ & $-0.07(0.17)$ & $<0.001$ \\
\hline $60-69$ & $0.03(0.15)$ & $<0.001$ & $0.00(0.16)$ & 0.503 \\
\hline $70-79$ & $0.04(0.16)$ & $<0.001$ & $0.01(0.18)$ & 0.594 \\
\hline$\geq 80$ & $0.00(0.15)$ & 0.751 & $-0.00(0.19)$ & 0.791 \\
\hline
\end{tabular}

${ }^{\star}$ The predicted equation for EQ-5D health utility was derived from the general population $0.84822-0.00208 \times$ (age -50$)-0.00002 \times$ $(\text { age-50) })^{2}-0.02090$ if women.

tp Value was obtained using one sample t-test.

$\ddagger$ The predicted equation for VAS was 83.183-0.199 (age-50)-0.006 (age-50) $2+0.401$ if women.

ACS, acute coronary syndromes; EQ-5D, EuroQol five-dimensional questionnaire; PCI, percutaneous coronary intervention; VAS, visual analogue scale.

mean value of 0.70 for EQ-5D. ${ }^{7}$ In a German registry of patients with MI, the reported mean EQ-5D was 0.87 $(0.15)$, while the VAS was $0.66(0.19) .{ }^{4}$ The variability of the EQ-5D HU across studies could be explained by different adaptations from EQ-5D into an aggregated HU value and by patient's characteristics. Prognosis of the ACS population has considerably improved with the use of PCI, and with the use of more effective pharmacological agents, such as statins and potent $\mathrm{P}_{2} \mathrm{Y}_{12}$ inhibitors. $^{6}$ Particularly, a cost-effectiveness analysis of clopidogrel was limited due to the absence of reliable estimates for $\mathrm{HU}$ in patients with ACS. ${ }^{10}$ This is especially important given that a reduction of 0.1 of $\mathrm{HU}$ in a sensitivity analysis could potentially change the costeffectiveness ratios in patients with ACS. ${ }^{10}$ In the PLATelet inhibition and patient Outcomes (PLATO) trial, cost-effectiveness analysis of the ticagrelor strategy versus clopidogrel strategy used a mean QALY of 0.846 in patients with ACS based on EQ-5D instrument. ${ }^{4}{ }^{5}$ Parameters for long-term extrapolation considered a QALY decrement of 0.075 for recurrent non-fatal MI and a decrement of 0.103 for non-fatal stroke. ${ }^{6}$ The adjustment according to age considered an estimate of 0.874 for those $<69$ years, 0.813 for those $70-79$ years and 0.754 for those $>79$ years. ${ }^{23}{ }^{24}$ However, those analyses did not specifically adapt HU estimates for important subgroups, such as diabetes, type of ACS, HF, education or attendance to $\mathrm{CR}^{4}{ }^{7}$

Strengths are the prospective nature of the study, the large number of patients with $>80 \%$ HU follow-up rate at 1 year, and the global assessments between patients' characteristics and HU.

Our study has several limitations. We measured HU by means of validated, but already existing simple assessment tools, such as EQ5D and VAS, but other concomitant questionnaires (eg, SF-36) or new assessment tools specifically designed for patients with ACS might have strengthened the findings. For instance, our data did not find significant differences of EQ-5D HU in patients with ACS compared with the general population in Switzerland, except for patients younger than 60 years old. One potential explanation is the favourable impact of modern therapies on the prognosis of ACS; an alternate hypothesis might be the lack of sensitivity of the EQ-5D HU to detect differences due to ceiling effects. ${ }^{11}$ Although we applied an equation based on age and gender developed in the general population to predict expected HU in the control group, the ACS cohort was different in terms of baseline characteristics (eg, higher proportion of women in the control group compared with the ACS population).

EQ-5D has been reported to be valid and reliable in patients with $\mathrm{CAD} .{ }^{8}$ The EQ-5D HU is able to detect clinical symptoms, such as severe angina or HF symptoms, and has been validated with disease-specific instrument, such as the Seattle Angina Questionnaire. We have previously reported that an HU assessment limited to five dimensions may miss important health issues in a large proportion of individuals. ${ }^{28}$ The addition of five alternative health dimensions (sleep, memory/concentration, fatigue/energy, sight/hearing and contact with others) was able to improve the variance of health status expressed in VAS. ${ }^{28}$ Nevertheless, EQ-5D was able to detect in our study the greater impact of ACS confirming the important effect of premature ACS on productivity and opportunity costs in younger patients. ${ }^{29}$

Self-reported health status measured by VAS has been used in large cardiovascular studies, such as the Bypass Angioplasty Revascularization Investigation 2 Diabetes. ${ }^{30}$ Some data suggest that self-rated health status is not only 
a spontaneous assessment of one's health status, but a marker of achievement of one's relatively important health-related goals. ${ }^{31}$ This might be particularly important in younger patients who tend to evaluate their health state more negatively. In addition, a subjective evaluation of the health status in patients with ACS could be additionally influenced by socioeconomic or psychological factors beyond standardised preferences of the EQ-5D instrument. Health economic studies are usually based on $\mathrm{HU}$ indexes derived from generic instruments, such as EQ-5D, while estimates derived from the VAS are more rarely used. ${ }^{9}$ Our data suggest that VAS could be more sensitive to detect differences of health loss in patients with ACS, compared with the EQ-5D instrument. In addition, our data suggest that aggregated estimates for health utility can miss important information emphasising the need of subgroup and scenario analyses.

Another limitation remains in the fact that our sample might not represent all patients who survived after ACS (selection bias). Indeed, not all individuals with cardiogenic shock or after resuscitation had been included in all centres, explained by the low mortality rate in the entire cohort. However, the mean age of patients included in our cohort was similar to another Swiss registry of patients with ACS, and also to the proportion of patients with heart failure at baseline. ${ }^{32}$ Although we applied an equation from the Swiss general population based on age and sex, it might be possible that differences between observed and predicted values were not only explained by ACS (eg, effect of smoking or low physical activity more prevalent in patients with ACS) leading to an overestimation of disutility of ACS. Thus, in the healthy control population cohort, there were $56 \%$ women, whereas in the patients' groups, $79.8 \%$ were men.

\section{Conclusion}

Our results suggest that EQ-5D health utility values are not significantly lower in patients with ACS referred for coronary angiography compared with the general population. Possibly, the EQ-5D instrument focusing on five dimensions does not capture the health utility accurately enough or, alternatively, it showed favourable impacts of contemporary ACS management more rapidly than global self-reported health utility. In contrast, if VAS detects significant differences of aggregated health utility values, it might be a more appropriate instrument in ACS patients. In addition, our study emphasises the relevance of patients' characteristics in the estimation of specific health utility indexes. Future patient-reported outcomes and health economic studies on ACS should address these patients' heterogeneity issues using subgroups, scenario and sensitivity analyses with probabilistic approaches to further reduce parameter uncertainty.

\section{Author affiliations}

${ }^{1}$ Cardiology Division, Geneva University Hospitals, University of Geneva, Geneva, Switzerland
${ }^{2}$ Department of General Internal Medicine, Inselspital, Bern University Hospital, University of Bern, Bern, Switzerland

${ }^{3}$ Department of Community Medicine and Ambulatory Care, University of Lausanne, Lausanne, Switzerland

${ }^{4}$ Department of Cardiology, Inselspital, Bern University Hospital, University of Bern, Bern, Switzerland

${ }^{5}$ Department of Cardiology, University Heart Center, Zurich, Switzerland ${ }^{6}$ Winterthur Institute of Health Economics, Zurich University of Applied Sciences, Winterthur, Switzerland

${ }^{7}$ Institute of Primary Health Care, University of Bern, Bern, Switzerland ${ }^{8}$ Applied Health Research Centre (AHRC), Li Ka Shing Knowledge Institute of St. Michael's Hospital, University of Toronto, Toronto, Canada

${ }^{9}$ Division of Clinical Epidemiology, University Hospital, Geneva, Switzerland

${ }^{10}$ Medical Directorate, University Hospital of Geneva, Geneva, Switzerland

${ }^{11}$ Department of Anaesthesiology, Clinical Pharmacology, and Intensive Care Medicine, University Hospitals of Geneva, Switzerland

\section{Twitter Follow Francois Girardin at @fg531}

Acknowledgements The authors thank Mathias Pfisterer, Basel, Lukas Kappenberger, Lausanne and Tiziano Moccetti, Lugano for assessing major cardiovascular events and bleeding in this ACS population. Furthermore, they thank the study nurses and staff of the catheter laboratories at the local sites for their invaluable help in the recruitment and assessment of the patients enrolled.

Contributors $B G$ and TP participated in the analysis of the study. BG and $F G$ have drafted the manuscript. RA, NR, LR, SW, FM, TFK, CMM, DN and BG have contributed to the data collection. All authors have made critical revision and approved the submitted version of the manuscript.

Funding ELIPS study was supported by the Swiss National Science Foundation (Special Programme University Medicine 'Acute Coronary Syndromes and Inflammation' SPUM 33CM30-124112 and SPUM 33CM30-140336 and by the Swiss Heart Foundation. Dr Gencer's research on cardiovascular prevention is supported by grants from the Geneva University Hospitals, the Swiss Heart Foundation and de Reuter Foundation.

Competing interests RK received honoraria from Eli Lilly, Servier and Bayer Healthcare. TFL has received honoraria from Amgen, AstraZeneca, Bayer Health Care and Eli Lilly; CMM has received honoraria from AstraZeneca, Daiichi-Sankyo, Eli Lilly, MSD and Roche. PJ is an unpaid steering committee or statistical executive committee member of trials funded by Abbott Vascular, Biosensors, Medtronic and St. Jude Medical. SW reports receiving research contracts to the institution from Abbott, Biotronik, Boston Scientific, Biosensors, Cordis, Medtronic, St. Jude Medical and speaker fees from: Abbott, Biotronik, Boston Scientific, Biosensors, Medtronic, Eli Lilly, Astra Zeneca. FM has received honoraria for advisory boards and conference on dyslipidaemia for Amgen, AstraZeneca, BMS, Eli Lilly, MSD, Sanofi and Pfizer.

Provenance and peer review Not commissioned; externally peer reviewed.

Open Access This is an Open Access article distributed in accordance with the Creative Commons Attribution Non Commercial (CC BY-NC 4.0) license, which permits others to distribute, remix, adapt, build upon this work noncommercially, and license their derivative works on different terms, provided the original work is properly cited and the use is non-commercial. See: http:// creativecommons.org/licenses/by-nc/4.0/

\section{REFERENCES}

1. Nichols M, Townsend N, Scarborough $P$, et al. Cardiovascular disease in Europe 2014: epidemiological update. Eur Heart $J$ 2014;35:2929.

2. Jernberg $\mathrm{T}$, Johanson $\mathrm{P}$, Held C, et al. Association between adoption of evidence-based treatment and survival for patients with ST-elevation myocardial infarction. JAMA 2011;305:1677-84.

3. Xie J, Wu EQ, Zheng ZJ, et al. Patient-reported health status in coronary heart disease in the United States: age, sex, racial, and ethnic differences. Circulation 2008;118:491-7.

4. Schweikert B, Hunger M, Meisinger C, et al. Quality of life several years after myocardial infarction: comparing the MONICA/KORA registry to the general population. Eur Heart J 2009;30:436-43. 
5. Drummond M, Sculpher MJ, Torrance G. Methods of the economic evaluation of health care programmes. 2005.

6. Hamm CW, Bassand JP, Agewall S, et al. ESC Guidelines for the management of acute coronary syndromes in patients presenting without persistent ST-segment elevation: the Task Force for the management of acute coronary syndromes (ACS) in patients presenting without persistent ST-segment elevation of the European Society of Cardiology (ESC). Eur Heart J 2011;32:2999-3054.

7. Sullivan PW, Ghushchyan V. Preference-Based EQ-5D index scores for chronic conditions in the United States. Med Decis Making 2006;26:410-20.

8. Dyer MT, Goldsmith KA, Sharples LS, et al. A review of health utilities using the EQ-5D in studies of cardiovascular disease. Health Qual Life Outcomes 2010;8:13.

9. Zhang Z, Kolm P, Grau-Sepulveda MV, et al. Cost-effectiveness of revascularization strategies: the ASCERT study. J Am Coll Cardiol 2015;65:1-11.

10. Lindgren $\mathrm{P}$, Stenestrand U, Malmberg K, et al. The long-term costeffectiveness of clopidogrel plus aspirin in patients undergoing percutaneous coronary intervention in Sweden. Clin Ther 2005;27:100-10.

11. Perneger TV, Combescure C, Courvoisier DS. General population reference values for the French version of the EuroQol EQ-5D health utility instrument. Value Health 2010;13:631-5.

12. Gencer B, Rodondi N, Auer R, et al. Reasons for discontinuation of recommended therapies according to the patients after acute coronary syndromes. Eur J Intern Med 2015;26:56-62.

13. Gencer B, Auer R, Nanchen D, et al. Expected impact of applying new 2013 AHA/ACC cholesterol guidelines criteria on the recommended lipid target achievement after acute coronary syndromes. Atherosclerosis 2015;239:118-24.

14. Thygesen K, Alpert JS, Jaffe AS, et al. Third universal definition of myocardial infarction. Eur Heart $J$ 2012;33:2551-67.

15. Mehran R, Rao SV, Bhatt DL, et al. Standardized bleeding definitions for cardiovascular clinical trials: a consensus report from the Bleeding Academic Research Consortium. Circulation 2011;123:2736-47.

16. Krabbe $\mathrm{P}$, et al. Guidelines for analysing and reporting EQ-5D outcomes. In: Brooks R, Rabib R, De Charro F, Eds. The measurement and valuation of health status using EQ-5D: a European perspective. Netherlands: Springer, 2003:7-19.

17. Ludt S, Wensing M, Szecsenyi J, et al. Predictors of health-related quality of life in patients at risk for cardiovascular disease in European primary care. PLOS ONE 2011;6:e29334.

18. Kim J, Henderson RA, Pocock SJ, et al. Health-related quality of life after interventional or conservative strategy in patients with unstable angina or non-ST-segment elevation myocardial infarction: one-year results of the third Randomized Intervention Trial of unstable Angina (RITA-3). J Am Coll Cardiol 2005;45:221-8.
19. Dempster M, Donnelly M. Measuring the health related quality of life of people with ischaemic heart disease. Heart 2000;83:641-4.

20. Dougherty CM, Dewhurst T, Nichol WP, et al. Comparison of three quality of life instruments in stable angina pectoris: Seattle Angina Questionnaire, Short Form Health Survey (SF-36), and Quality of Life Index-Cardiac Version III. J Clin Epidemiol 1998;51:569-75.

21. Wallentin L, Becker RC, Budaj A, et al. Ticagrelor versus clopidogrel in patients with acute coronary syndromes. $N$ Engl $\mathrm{J} \mathrm{Med}$ 2009;361:1045-57.

22. Leung Yinko SS, Pelletier R, Behlouli $\mathrm{H}$, et al. Health-related quality of life in premature acute coronary syndrome: does patient sex or gender really matter? J Am Heart Assoc 2014;3:pii: e000901.

23. Fryback DG, Dasbach EJ, Klein R, et al. The beaver dam health outcomes study: initial catalog of health-state quality factors. Med Decis Making 1993;13:89-102.

24. Nikolic E, Janzon M, Hauch O, et al. Cost-effectiveness of treating acute coronary syndrome patients with ticagrelor for 12 months: results from the PLATO study. Eur Heart $J$ 2013;34:220-8.

25. Levin LÅ, Wallentin L, Bernfort $L$, et al. Health-related quality of life of ticagrelor versus clopidogrel in patients with acute coronary syndromes-results from the PLATO trial. Value Health 2013;16:574-80.

26. Janzon M, James S, Cannon CP, et al. Health economic analysis of ticagrelor in patients with acute coronary syndromes intended for non-invasive therapy. Heart 2015;101:119-25.

27. Cowper PA, Pan W, Anstrom KJ, et al. Economic analysis of ticagrelor therapy from a U.S. perspective: results from the PLATO study. J Am Coll Cardiol 2015;65:465-76.

28. Perneger TV, Courvoisier DS. Exploration of health dimensions to be included in multi-attribute health-utility assessment. Int J Qual Health Care 2011;23:52-9.

29. Khan NA, Daskalopoulou SS, Karp I, et al. Sex differences in acute coronary syndrome symptom presentation in young patients. JAMA Intern Med 2013;173:1863-71.

30. Thomas SB, Sansing VV, Davis A, et al. Racial differences in the association between self-rated health status and objective clinical measures among participants in the BARI 2D trial. Am J Public Health 2010;100(Suppl 1):S269-76.

31. Bailis DS, Segall A, Chipperfield JG. Two views of self-rated general health status. Soc Sci Med 2003;56:203-17.

32. Erne P, Radovanovic D, Seifert B, et al. Outcome of patients admitted with acute coronary syndrome on palliative treatment: insights from the nationwide AMIS Plus Registry 1997-2014. BMJ Open 2015;5:e006218. 